\title{
Concentration of anti-Müllerian hormone in dairy heifers is positively associated with productive herd life
}

\author{
F. Jimenez-Krassel, ${ }^{\star} \dagger$ D. M. Scheetz, $\ddagger$ L. M. Neuder,§ J. L. H. Ireland, ${ }^{\dagger} \dagger$ J. R. Pursley,† G. W. Smith, $† \#$ \\ R. J. Tempelman, † T. Ferris,† W. E. Roudebush,ll F. Mossa,ף P. Lonergan, ${ }^{* *}$ A. C. O. Evans, ${ }^{* *}$ \\ and J. J. Ireland* ${ }^{1}$ \\ *Molecular Reproductive Endocrinology Laboratory, and \\ †Department of Animal Science, Michigan State University, East Lansing 48824-1225 \\ $\ddagger$ Accenture, Chicago, IL 60601 \\ §Department of Large Animal Clinical Sciences, Michigan State University, East Lansing 48824-1225 \\ \#Laboratory of Mammalian Reproductive Biology and Genomics, Michigan State University, East Lansing 48824-1225 \\ IIUniversity of South Carolina School of Medicine, Greenville 29605 \\ TUniversità degli Studi di Sassari, Dipartimento di Medicina Veterinaria, 07100 Sassari, Italy \\ ${ }^{* \star}$ School of Agriculture and Food Science, University College Dublin, Belfield, Dublin 4, Ireland
}

\section{ABSTRACT}

Reliable biomarkers predictive of productive herd life (time in herd after birth of first calf) have heretofore not been discovered in dairy cattle. However, circulating concentrations of anti-Müllerian hormone (AMH) are positively associated with number of follicles or antral follicle count (AFC), ovarian function, and fertility, and approximately $25 \%$ of cows have a relatively low AFC and low AMH concentrations. The present study tested the hypothesis that heifers with the lowest AMH concentrations have suboptimal fertility and are removed from a herd for poor reproductive performance at a greater rate, and therefore have a shorter productive herd life compared with age-matched herdmates with higher AMH. To test this hypothesis, 11- to 15-mo-old Holstein heifers $(\mathrm{n}=281)$ were subjected to a single measurement of AMH. All heifers not removed from the herd had the opportunity to complete 2 lactations and start their third lactation after calving. During this time, performance and health parameters for each individual were recorded daily by herd managers. Results showed that the quartile of heifers with the lowest $\mathrm{AMH}$ concentration also had, on average, a shorter productive herd life (by 196 d), a reduced survival rate after birth of the first calf, the lowest level of milk production (first lactation), the lowest total percentage of cows pregnant (across all lactations), the highest culling rates (first and second lactations and overall), and the highest culling rate for poor reproduction (first lactation) compared with age-matched herdmates with

Received March 12, 2014.

Accepted January 12, 2015.

${ }^{1}$ Corresponding author: ireland@msu.edu higher AMH. We concluded that a single determination of AMH concentration in young adult dairy heifers may be a simple diagnostic method to predict herd longevity, and AMH may be a useful phenotypic marker to improve longevity of dairy cows.

Key words: anti-Müllerian hormone (AMH), culling rate, longevity, productive herd life, survival rate

\section{INTRODUCTION}

Heritability estimates of the number of days that dairy cattle remain in herds (herd longevity) are very low (0.03 to 0.07; VanRaden et al., 2006; reviewed by Singhapol and Muller, 2011). However, biomarkers that are moderately to highly heritable and highly correlated with longevity have not been discovered. Discovery of such biomarkers would benefit not only identification of females with potentially enhanced future herd longevity, but also sire selection and breeding programs designed to genetically improve survival rates and thus productive herd life of dairy cows and profitability of the dairy industry.

Cattle can be phenotyped reliably based on antral follicle count (AFC), defined as the average for maximum number of antral follicles $\geq 3 \mathrm{~mm}$ in diameter counted during each of the 2 or 3 consecutive follicular waves during an estrous cycle (Burns et al., 2005). Our studies show that despite high variability in AFC during follicular waves (range $=8$ to 56 follicles) among cattle, AFC is highly repeatable within individuals (Burns et al., 2005; Ireland et al., 2007) and highly positively associated with ovary size and total number of morphologically healthy follicles and oocytes in ovaries (ovarian reserve; Ireland et al., 2008). In addition, AFC is a reliable phenotypic biomarker positively associated with ovarian function (Ireland et 
al., 2009; Jimenez-Krassel et al., 2009), responsiveness to superovulation, number of transferable embryos, in vitro blastocyst production, fertility (Cushman et al., 2009; Mossa et al., 2012), and birth weight (Cushman et al., 2009). Young adult cattle with a relatively low $\mathrm{AFC}$ versus a high AFC also have much lower circulating progesterone concentrations during estrous cycles (Jimenez-Krassel et al., 2009), which are known to be associated with high rates of embryo mortality in cattle (Inskeep, 2004; Diskin and Morris, 2008). In support of potentially higher rates of embryo mortality in cattle with a low AFC, we have recently shown that reproductive performance is inferior in dairy cows with relatively low AFC compared with a higher AFC (Mossa et al., 2012). Many of the phenotypic differences between young adult cattle with a relatively low $(\leq 15$ follicles $\geq 3 \mathrm{~mm}$ in diameter) AFC (Burns et al., 2005; Ireland et al., 2007; Mossa et al., 2012), which comprise 20 to $25 \%$ of a herd (Burns et al., 2005; Ireland et al., 2007; Mossa et al., 2012), are also reported for older, lessfertile cattle (Lucy, 2001; Sartori et al., 2002b; Malhi et al., 2005) compared with their younger counterparts. Taken together, these results supported the hypothesis that healthy young adult heifers with a relatively low AFC are removed (culled) from herds by management at higher rates for inferior reproductive performance and thus have a shorter productive herd life compared with age-matched herdmates with a higher AFC.

Anti-Müllerian hormone (AMH) is a growth factor in the transforming growth factor (TGF) $\beta$ superfamily that is secreted exclusively by granulosa cells of healthy, growing follicles (La Marca and Volpe, 2006). Concentration of $\mathrm{AMH}$ and $\mathrm{AFC}$, both of which are highly repeatable within individuals (Burns et al., 2005; Ireland et al., 2007, 2011), are also highly positively correlated $(\mathrm{r}=0.88)$ with each other (Ireland et al., 2008,2011 ) and with the size of the ovarian reserve (r $=0.90$ ) in cattle (Ireland et al., 2008). Although AMH concentrations are highly variable among animals, as are follicle numbers, our studies show that the day-today alterations in $\mathrm{AMH}$ concentrations are relatively static during reproductive cycles within individual heifers (Ireland et al., 2008), as also reported for cows (Rico et al., 2009, 2011). For example, a single AMH measurement in young adult heifers is highly correlated $(\mathrm{r}=0.97)$ with the average for multiple AMH measurements during different days of the same or multiple estrous cycles and with ovary size and AFC (Ireland et al., 2011). Therefore, to test the aforementioned hypothesis, the objective of the present study was to determine if a single AMH measurement in dairy heifers is predictive of subsequent lifetime performance, survival, and longevity in the dairy herd.

\section{MATERIALS AND METHODS}

All experiments involving cattle were approved by the Institutional Animal Care and Use Committee at Michigan State University. Our project was initiated September 5, 2008, and ended December 5, 2012. Adult Holstein heifers ( $\mathrm{n}=281,11$ to 15 mo old; located on Green Meadow Farms Inc., Ovid-Elsie, MI) were subjected once to 2 intramuscular injections of $\mathrm{PGF}_{2 \alpha}$ spaced $11 \mathrm{~d}$ apart to synchronize estrous cycles. At $96 \mathrm{~h}$ after the last $\mathrm{PGF}_{2 \alpha}$ injection, a single tail-vein blood sample was taken from each of the 281 heifers to measure serum AMH and establish the relative size of the ovarian reserve (Ireland et al., 2008). After completion of the $\mathrm{PGF}_{2 \alpha}$-induced estrous cycle, heifers were observed for signs of estrus twice a day and then subjected to AI the next morning after standing estrus; heifers returning to estrus were re-inseminated up to 6 times. Diagnosis of pregnancy was done by palpation of uterine contents or ultrasonography between 45 and $60 \mathrm{~d}$ after AI. Heifers diagnosed as not pregnant were subjected to AI, as just explained.

After calving, lactating cows were subjected to a Presynch14/Ovsynch program (El-Zarkouny et al., 2004). Briefly, between 47 and 53 DIM, all lactating cows received 2 injections of $\mathrm{PGF}_{2 \alpha}$ spaced $14 \mathrm{~d}$ apart. Cows exhibiting standing estrus were subjected to AI (at approximately $63 \mathrm{DIM}$ ) after the second $\mathrm{PGF}_{2 \alpha}$ injection. Detection of estrus was performed 3 times daily. Cows not bred after the second $\mathrm{PGF}_{2 \alpha}$ injection were subjected to Ovsynch beginning $11 \mathrm{~d}$ after the second $\mathrm{PGF}_{2 \alpha}$ injection followed by $\mathrm{AI}$ at a fixed time interval (Pursley et al., 1995). Pregnancy status was assessed by palpation or ultrasonography of uterine contents approximately $35 \mathrm{~d}$ after AI. Cows returning to estrus before pregnancy diagnosis were inseminated at standing estrus. Animals diagnosed as not pregnant were subjected to AI at standing estrus after either a single $\mathrm{PGF}_{2 \alpha}$ injection (if a corpus luteum was present) or given a $\mathrm{GnRH}$ injection followed by a $\mathrm{PGF}_{2 \alpha}$ injection $7 \mathrm{~d}$ later (if a corpus luteum was not present). This breeding regimen in cows continued up to 4 to 5 times.

Records on reproductive performance, level of milk production, health, and reasons for culling of each individual animal were maintained in an on-the-farm computer using the commercial DairyComp 305 software program (VAS, 2011). Relevant information for each cow was recorded daily by managers and select employees. The following 16 involuntary and 3 voluntary reasons were used at the farm to describe why cows were removed or culled from the herd: involuntaryreproductive problems $(\geq 4$ inseminations without pregnancy, cystic follicles, excessive fat around ovaries 
Table 1. Summary of anti-Müllerian hormone (AMH) concentrations (range in parentheses), number of started and completed lactations ( \pm SEM), and productive herd life ( \pm SEM) for Holstein cows in each AMH quartile

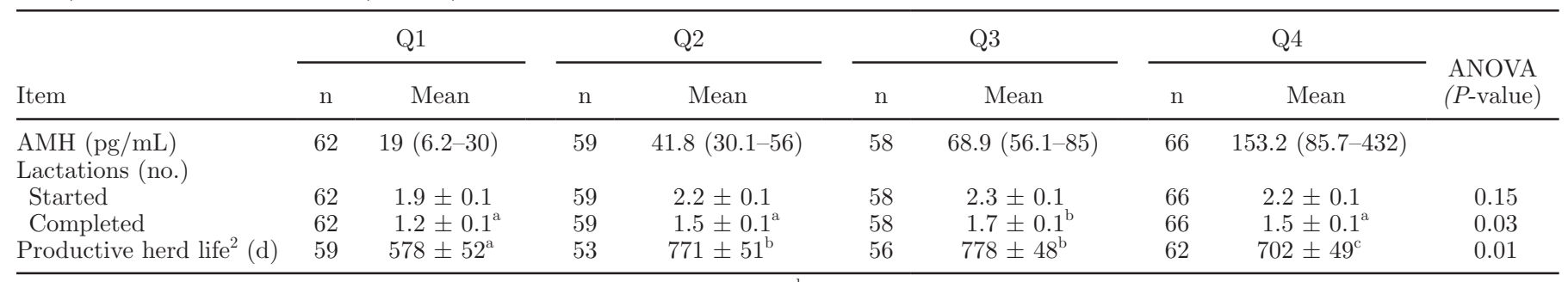

${ }^{\mathrm{a}-\mathrm{c}}$ Means with different superscripts within a row differed significantly $\left({ }^{\mathrm{ab}} P<0.05 ;{ }^{\mathrm{ac}} P<0.07\right)$ from means in Q1.

${ }^{1}$ Concentration of AMH was measured in 11- to 15-mo-old Holstein heifers, and animals were divided into quartiles (Q1 to Q4) based on AMH concentrations (e.g., Q1 = quartile of heifers with lowest AMH).

${ }^{2}$ Defined as days in herd after birth of first calf.

making palpation and breeding difficult, abortions), mastitis, injury/accident, calving injury, metritis/ retained placenta, displaced abomasum, death, lameness, metabolic syndrome, infections, lost records, or unknown; voluntary - low milk production, poor conformation, or sold as replacement to other dairy farmers. All culling decisions were made without knowledge of AMH concentrations of the animals involved in the present study. Whether the proportion of cows removed from the herd for each of the aforementioned involuntary or voluntary reasons was associated with $\mathrm{AMH}$ concentrations in the same individuals as 11- to 15-moold heifers was determined once animals were $\sim 5$ yr old.

\section{AMH Assay}

The commercially available human AMH Gen II ELISA kit (Beckman-Coulter Inc., Brea, CA) was used to measure serum AMH concentrations in cattle per kit instructions. The 2-site AMH assay was validated by us (Ireland et al., 2008) for use in cattle and does not cross react with other members of the TGF $\beta$ superfamily including TGF $\beta$, bone morphogenic factor-4 (BMP4), inhibin, or activin (Kevenaar et al., 2006). Because AMH concentrations are relatively low in bovine compared with humans (La Marca et al., 2006), the only modification in the assay was to measure duplicate $40-\mu \mathrm{L}$ rather than $20-\mu \mathrm{L}$ volumes of serum during assays. The inter- and intraassay coefficient of variation was $\leq 6.9 \%$ ( $\mathrm{n}=11$ assays $)$.

\section{Statistical Analysis}

To test the hypothesis that heifers with the lowest AMH concentrations are removed from a herd for poor reproductive performance at a greater rate and have a shorter productive herd life and survival rate compared with age-matched herdmates with higher AMH, cows were partitioned into quartiles $(\mathbf{Q 1}, \mathbf{Q} 2, \mathbf{Q 3}, \mathbf{Q} 4)$ based on AMH concentrations (e.g., Q1 had the lowest AMH concentration; Table 1) as 11- to 15-mo-old heifers. Animals that were voluntarily sold as dairy replacements to other farmers after AMH measurements were made were not included in the analyses. All statistical analyses were done using SAS procedures (SAS Institute, 2010) and all data were log-transformed before analyses. Analysis of variance was used to determine if significant $(P \leq 0.05)$ overall differences existed among different quartiles for all variables, such as number of AI, days open, level of milk production as determined by 305-d mature equivalent yields, number of lactations started and completed, and productive herd life. Productive herd life was defined as the period between first calving and culling or the end of the study. If the ANOVA was significant $(P<0.05)$, Bonferroni- $t$-test was used to determine which means differed $(P \leq 0.05)$ from each other.

During survival analyses, censored records represent cows that were culled for various reasons, sold, or died, whereas uncensored cows remain in the herd. Proportion of cows remaining in the herd (survival rate) was evaluated using Kaplan-Meier curves for each AMH quartile, and differences between quartiles were analyzed using the Cox proportional hazard model. The hazard ratio is defined as the probability (relative risk) that Q2, Q3, and Q4 cows would be culled compared with Q1 cows after birth of the first calf (Pankowski et al., 1995). Survival was expressed as the relative hazard of a cow being culled on day $t$, given that it had not been culled at day $t-1$, in the exposed group relative to the reference group (Q1). Therefore, a hazard ratio (HR) of 1 represents an equal likelihood of a cow being culled at time $t$ compared with a contemporary in Q1, whereas a lower HR indicates a decreased likelihood of an animal being culled at time $t$ compared with Q1.

The potential correlation between AMH concentrations and level of milk production was determined by Pearson correlations. Logistic regression analyses were 
used to determine if overall culling rates, conception rates to the first $\mathrm{AI}$, and total percentage of cows pregnant differed among quartiles during each of 3 subsequent lactations.

The 19 voluntary and involuntary culling reasons used by management at Green Meadow Farms were combined into the following 5 primary herd removal (culling) reasons for statistical analysis: (1) poor reproductive performance ( $\geq 4$ AI without pregnancy, cystic ovaries, fat around ovaries, abortions), (2) death, (3) health (mastitis, lameness, metritis/retained placenta, infection, metabolic syndrome, displaced abomasum), (4) voluntary (low milk production and poor conformation), and (5) other (injury/accidents, unknown). A multinomial logistic regression analysis tested whether the frequency of the 5 major reasons why individuals were removed from herds differed $(P<0.05)$ among the different quartiles by the end of each of 3 subsequent lactations using CATMOD procedure of SAS (SAS Institute, 2010) as reported by others (Núñez-Dominguez et al., 1991).

\section{RESULTS}

Distribution of heifers by AMH concentration is shown in Figure 1, and mean AMH concentration for each quartile of heifers is in Table 1. Age of animals at their first $\mathrm{PGF}_{2 \alpha}$ injection, first $\mathrm{AI}$, and conception, and at each calving did not differ among the different $\mathrm{AMH}$ quartiles (Table 2). Although the number of lactations started was similar among quartiles, Q1 cows with the lowest AMH concentrations as heifers completed fewer $(P<0.05)$ lactations compared with Q3 cows. The Q1 cows also had a shorter $(P<0.05)$ productive herd life compared with Q2 or Q3, which was, for example, $196 \mathrm{~d}$ less than the average productive herd life for Q2 and Q3 cows combined (Table 1). We also detected a tendency $(P<0.07)$ for Q1 cows to have a shorter productive herd life compared with Q4 cows.

By the end of our study, 24, 37, 43, and $32 \%$ of the cows in Q1, Q2, Q3, and Q4, respectively, remained in the herd. Results of survival analysis showed that the

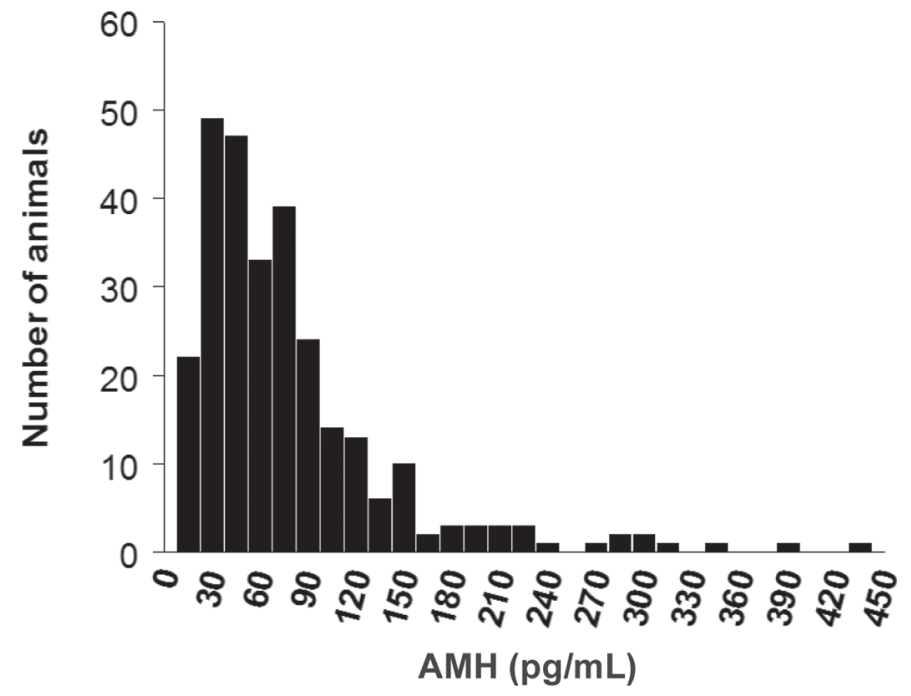

Figure 1. Frequency distribution for number of Holstein heifers at each different anti-Müllerian hormone (AMH) concentration. Concentrations ranged from 6 to $440 \mathrm{pg} / \mathrm{mL}$, and each bar depicts increments of $15 \mathrm{pg} / \mathrm{mL}$. For example, first 2 bars reflect the number of animals that had AMH concentrations between 0 and $30 \mathrm{pg} / \mathrm{mL}$, whereas the next 2 bars reflect number of animals that had AMH concentrations between 30.1 and $60 \mathrm{pg} / \mathrm{mL}$.

proportion of cows remaining in the herd (survival rate) differed $(P=0.03)$ among the AMH quartiles (Figure 2 ). For example, the probability of being culled after birth of the first calf was lower for Q2 $(\mathrm{HR}=0.57, P$ $<0.02)$ and $\mathrm{Q} 3(\mathrm{HR}=0.54, P<0.01)$ compared with Q1 cows, and there was a tendency that the probability of being culled was lower for $\mathrm{Q} 4(\mathrm{HR}=0.72, P=0.13)$ compared with Q1 cows (Figure 2).

The shorter productive herd life and lower survival rate for Q1 cows implied that the culling rate for these individuals was higher compared with that of their Q2, Q3, and Q4 herdmates. In support of this possibility, culling rates for all reasons combined were higher $(P<$ 0.05) for Q1 compared with Q2 and Q3 cows during the first lactation and compared with Q2 cows during the second lactation and for all lactations combined (Table $3)$. The precise reason that individuals in the different quartiles were removed from the herd was examined for

Table 2. Age $(\mathrm{d} ; \pm \mathrm{SEM})$ of Holstein heifers at time of first $\mathrm{PGF}_{2 \alpha}$ injection (start of longevity trial), first AI, and at conception, and age of cows at first, second, and third calvings

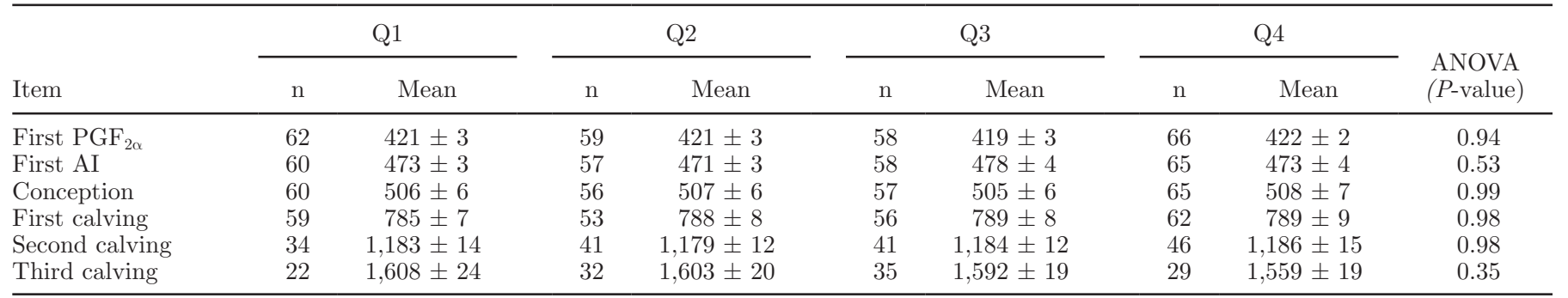




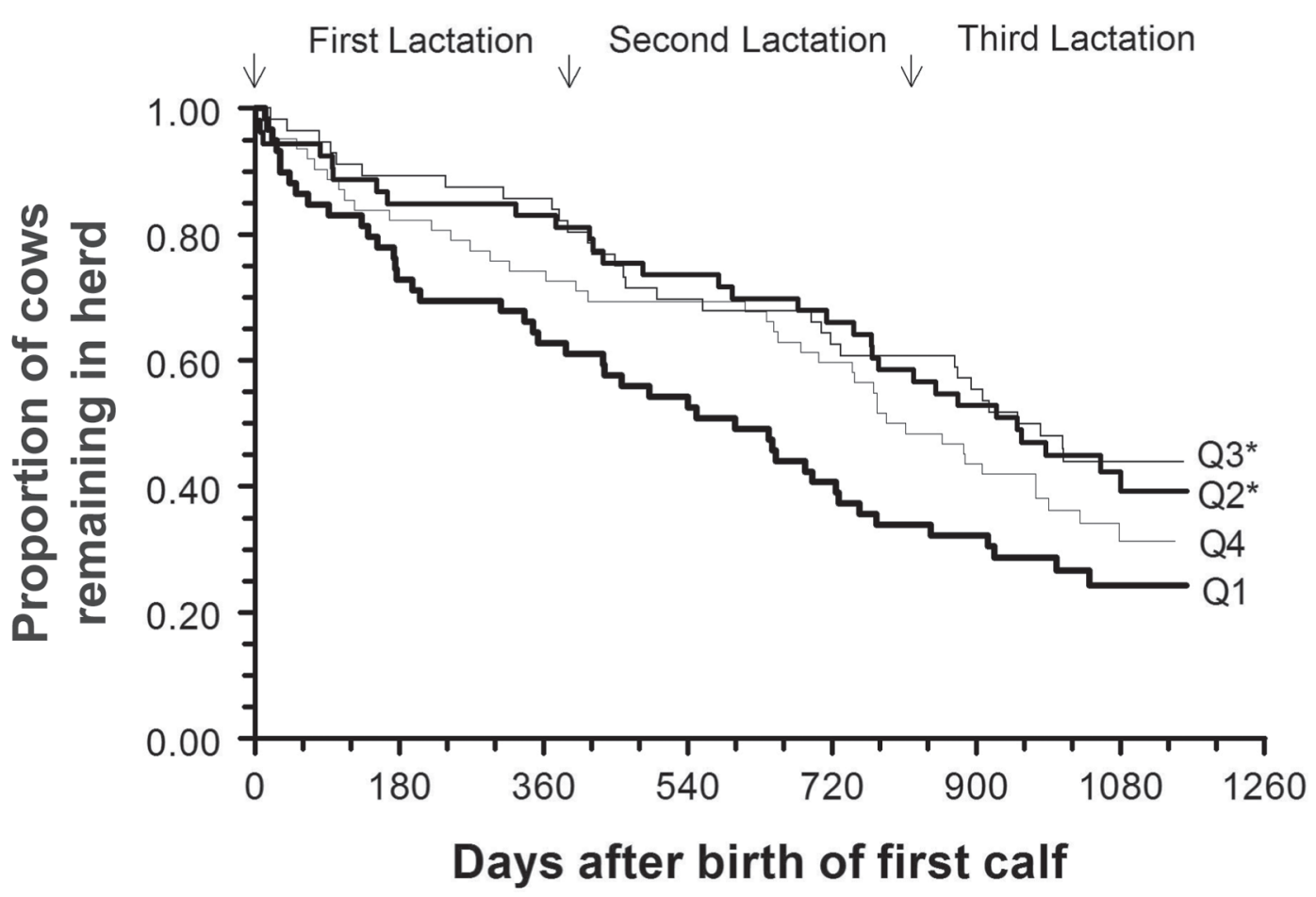

Figure 2. Kaplan-Meier plots of survival curves for proportion of Holstein cows in each anti-Müllerian hormone (AMH) quartile (where Q1 $=$ quartile of heifers with lowest AMH concentration) remaining in the herd after birth of their first calf. Asterisk indicates that survival rate for Q1 differs from that for Q2 $(P<0.02)$ or Q3 $(P<0.01)$; survival rate in Q1 tended $(P=0.13)$ to differ from that in Q4.

heifers and for cows during different lactations. Results of multinomial logistic regression analysis showed that removal rate for poor reproductive performance compared with all other reasons for culling [e.g., voluntary (level of milk production, poor conformation), death, health (mastitis, lameness), or other] was greater ( $P$ $<0.05$ ) for Q1 compared with Q2, Q3, and Q4 cows combined during the first lactation (Table 3 ).

Although culling for voluntary reasons, which included level of milk production, was similar among quartiles in our study, level of milk production, as assessed by 305-d mature-equivalent yield, was nevertheless lower $(P<0.03)$ in $\mathrm{Q} 1$ compared with $\mathrm{Q} 2$ or Q3 cows during the first lactation, but did not differ among $\mathrm{AMH}$ quartiles during subsequent lactations (Table 4). Moreover, regression analysis showed that no significant correlation existed between AMH concentrations and milk production levels during any lactation (data not shown).

Because culling rates for poor reproductive performance were highest for Q1 cows during the first lactation, we also analyzed several measures of reproductive performance, including number of times subjected to AI per conception, days open, and calving intervals, but none of these parameters differed $(P>0.10)$ among quartiles (Table 5). Conception rates after the first AI before (as heifers) and during the first, second, and third lactations averaged $44.5 \%$ ( $\mathrm{n}=240$ animals $)$, $37 \%(\mathrm{n}=202), 27 \%(\mathrm{n}=150)$, and $34 \%(\mathrm{n}=89)$, respectively, but did not differ $(P>0.10)$ among quartiles for heifers or during the different lactations (Table 5). Total percentage pregnant was also similar among quartiles for heifers and for cows during different lactations. However, total percentages of cows pregnant for all lactations combined was lower $(P<0.01)$ for cows in Q1 compared with Q2 or Q3, but was not different from Q4 (Table 5).

\section{DISCUSSION}

The most significant finding of the present study was that dairy cows (Q1) with relatively low circulating $\mathrm{AMH}$ concentrations as heifers also had the lowest survival rate after birth of their first calf compared with age-matched herdmates [Q2, Q3, Q4 (tendency)] with higher AMH concentrations as heifers. This key observation was confirmed by our finding that productive herd life, which measures the length of time an animal is in the herd after calving until culling or the end of our study, was almost 6 mo shorter for Q1 compared with the overall average productive herd life for Q2, Q3, and Q4 cows combined. Taken together, these 
Table 3. Culling rates for reproduction, death, health, voluntary, and other reasons for heifers and cows during their first, second and third lactation

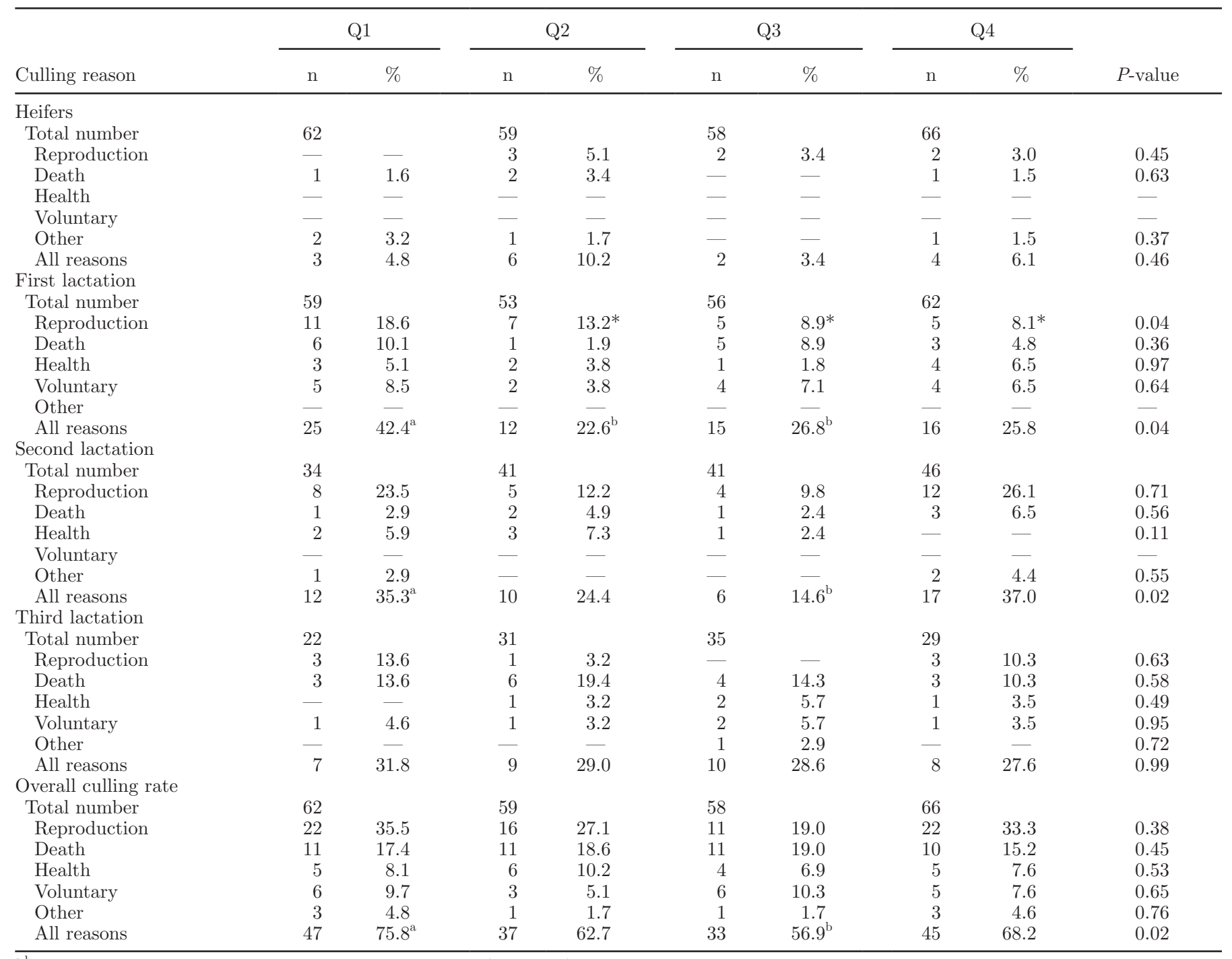

${ }^{\mathrm{a}, \mathrm{b}}$ Values with different superscripts within a row differ $(P<0.05)$ between Q2, Q3, or Q4 and Q1 after logistic regression analyses.

*Difference $(P=0.04)$ between Q1 and Q2, Q3, and Q4 combined after multinomial logistic regression analyses.

Table 4. Summary of milk production levels (305-d mature-equivalent yield; $\mathrm{kg}$ ) during the first 3 lactations in each anti-Müllerian hormone $(\mathrm{AMH})$ quartile $^{1}$

\begin{tabular}{|c|c|c|c|c|c|c|}
\hline \multirow{2}{*}{$\begin{array}{l}\text { AMH } \\
\text { quartile }\end{array}$} & \multicolumn{2}{|c|}{ First lactation } & \multicolumn{2}{|c|}{ Second lactation } & \multicolumn{2}{|c|}{ Third lactation } \\
\hline & $\mathrm{n}$ & Mean \pm SEM & $\mathrm{n}$ & Mean \pm SEM & $\mathrm{n}$ & Mean \pm SEM \\
\hline Q1 & 61 & $12,223 \pm 369^{\mathrm{b}}$ & 34 & $14,021 \pm 390$ & 20 & $12,580 \pm 447$ \\
\hline Q2 & 58 & $13,598 \pm 318^{\mathrm{a}}$ & 40 & $14,436 \pm 319$ & 30 & $12,134 \pm 278$ \\
\hline Q3 & 62 & $13,381 \pm 368^{\mathrm{a}}$ & 42 & $14,044 \pm 333$ & 34 & $12,055 \pm 353$ \\
\hline Q4 & 61 & $12,984 \pm 351^{\mathrm{ab}}$ & 44 & $14,573 \pm 279$ & 27 & $13,099 \pm 291$ \\
\hline Total & 242 & $13,041 \pm 179$ & 160 & $14,283 \pm 163$ & 111 & $12,425 \pm 172$ \\
\hline
\end{tabular}

${ }_{\mathrm{a}, \mathrm{b}}$ Means with different superscripts within a column indicate a significant difference $(P<0.04)$.

${ }^{1}$ Concentration of AMH was measured in 12-15 mo old Holstein heifers, and animals were divided into quartiles (Q1 to Q4) based on AMH concentrations (e.g., Q1 = quartile of heifers with lowest AMH). Only cows with at least $30 \mathrm{~d}$ of milk production were included in this analysis. 
Table 5. Reproductive parameters in Holstein heifers and cows at their first, second, and third lactations

\begin{tabular}{|c|c|c|c|c|c|c|c|c|c|}
\hline Item $^{1}$ & \multicolumn{2}{|r|}{ Q1 } & \multicolumn{2}{|r|}{ Q2 } & \multicolumn{2}{|r|}{ Q3 } & \multicolumn{2}{|r|}{ Q4 } & $P$-value \\
\hline \multicolumn{10}{|l|}{ Heifers } \\
\hline $\mathrm{CR}(\%)$ & 60 & $47 \pm 6$ & 57 & $37 \pm 6$ & 58 & $48 \pm 7$ & 65 & $46 \pm 6$ & 0.60 \\
\hline TPP (\%) & 60 & $98 \pm 2$ & 57 & $92 \pm 3$ & 58 & $97 \pm 2$ & 65 & $95 \pm 3$ & 0.57 \\
\hline \multicolumn{10}{|c|}{ First lactation } \\
\hline TPP (\%) & 49 & $69 \pm 7$ & 49 & $84 \pm 5$ & 51 & $85 \pm 5$ & 53 & $87 \pm 5$ & 0.12 \\
\hline \multicolumn{10}{|c|}{ Second lactation } \\
\hline $\mathrm{CI}(\mathrm{d})$ & 34 & $392 \pm 8$ & 41 & $397 \pm 8$ & 41 & $397 \pm 10$ & 46 & $398 \pm 8$ & 0.97 \\
\hline $\mathrm{DO}(\mathrm{d})$ & 34 & $168 \pm 15$ & 41 & $158 \pm 15$ & 41 & $138 \pm 12$ & 46 & $167 \pm 16$ & 0.45 \\
\hline $\mathrm{SPC}$ (no.) & 32 & $3.2 \pm 0.3$ & 39 & $3.3 \pm 0.3$ & 38 & $2.8 \pm 0.3$ & 41 & $2.9 \pm 0.3$ & 0.65 \\
\hline CR $(\%)$ & 32 & $28 \pm 8$ & 39 & $26 \pm 7$ & 38 & $26 \pm 7$ & 41 & $29 \pm 7$ & 0.98 \\
\hline CR (\%) & 17 & $24 \pm 11$ & 22 & $36 \pm 10$ & 25 & $40 \pm 10$ & 25 & $36 \pm 10$ & 0.74 \\
\hline TPP (\%) & 17 & $71 \pm 11$ & 22 & $82 \pm 8$ & 25 & $92 \pm 5$ & 25 & $72 \pm 9$ & 0.28 \\
\hline \multicolumn{10}{|c|}{ Overall averages for lactations } \\
\hline CI $(d)$ & 34 & $401 \pm 7$ & 41 & $405 \pm 7$ & 41 & $397 \pm 7$ & 46 & $393 \pm 6$ & 0.72 \\
\hline $\mathrm{DO}(\mathrm{d})$ & 59 & $143 \pm 9$ & 53 & $136 \pm 8$ & 56 & $135 \pm 8$ & 62 & $138 \pm 7$ & 0.82 \\
\hline $\mathrm{SPC}$ (no.) & 49 & $2.8 \pm 0.2$ & 49 & $2.6 \pm 0.2$ & 51 & $2.7 \pm 0.2$ & 53 & $2.5 \pm 0.1$ & 0.52 \\
\hline CR $(\%)$ & 49 & $28 \pm 4$ & 49 & $35 \pm 5$ & 51 & $33 \pm 4$ & 53 & $36 \pm 4$ & 0.62 \\
\hline $\operatorname{TPP}(\%)$ & 49 & $71 \pm 6^{\mathrm{b}}$ & 40 & $85 \pm 3^{\mathrm{a}}$ & 51 & $89 \pm 3^{\mathrm{a}}$ & 53 & $79 \pm 4^{\mathrm{ab}}$ & 0.01 \\
\hline
\end{tabular}

$\overline{\mathrm{a}, \mathrm{b}}$ Means with different superscripts within a row differed significantly $(P<0.01)$.

${ }^{1} \mathrm{SPC}=$ services per conception; $\mathrm{CR}=$ conception rate at first $\mathrm{AI}$; TPP $=$ total percentage pregnant; DO $=$ days open; $\mathrm{CI}=$ calving intervals. Overall averages do not include data from heifers.

novel observations imply that a single determination of $\mathrm{AMH}$ in 11- to 15-mo-old Holstein heifers is predictive of their future herd longevity. Economic value for herd longevity or productive life of cows ranges from $\$ 24$ to $\$ 35$ per month based on values for PTA for Productive Life (PTAPL) in the USDA Net Merit Index (Cole and VanRaden, 2009; VanRaden and Cole, 2014). For example, for each heifer replaced from the bottom $25 \%$ (Q1) with a heifer from the top 75\% (Q2 to Q4) in the present study, there would be an increase of $172 \mathrm{~d}$ of herd life, which equates to an increase in income per animal of $\$ 137$ to $\$ 200$. Thus, another significant finding of the present study is the observation that a single AMH measurement in young adult heifers may be a simple diagnostic method to identify superior heifers, thereby improving profitability of the dairy operation.

Most reproductive traits are lowly heritable (0.02 to 0.04; Berry et al., 2014). However, AFC, which are highly correlated with AMH concentrations in heifers, size of the ovarian reserve, and ovarian function in cattle, were shown to be a moderately heritable in dairy cows $(0.31 \pm 0.14)$ and heifers $(0.25 \pm 0.13$; Walsh et al., 2014). Level of milk production was not correlated with AMH concentration in heifers in the present study. Thus, the ability to use relatively high AMH concentrations to identify superior heifers to retain in the herd without compromising milk production could become a valuable reproductive management tool to reduce involuntary culling in herds, especially as the use of sexed semen from genetically superior bulls to produce excess heifers for herd replacements becomes more widespread in the dairy industry (Hohenboken, 1999; Weigel, 2004; Cerchiaro et al., 2007; De Vries et al., 2008). Moreover, genome-wide association studies based on use of high-density SNP marker panels (Seidel, 2010) could be used to search for genes associated with AMH concentrations and, correspondingly, ovary size and function and size of the ovarian reserve, which are traits apparently unrelated to level of milk production (as observed in the present study). Availability of these AMH-related genetic markers would enable reliable identification of high-genetic-merit males for artificial breeding programs designed to genetically improve reproductive performance, health, and herd longevity of dairy cows. For example, $\mathrm{AMH}$ and (or) AMH-related genetic markers could be incorporated into USDA-Council on Dairy Cattle Breeding (CDCB) calculations for PTAPL to improve accuracy and allow 
selection of sires with daughters that have high AMH concentrations.

Survival rate and productive herd life were much shorter for cows with relatively low AMH concentrations as young adults. However, determining the precise reason for this finding was likely hindered somewhat in the present study by the limited number of animals in each quartile and potentially by a lack of rigorously defined and consistently adhered-to quantitative reasons for removal of cows from the herd by management (Lehenbauer and Oltjen, 1998). Nevertheless, the significantly diminished herd longevity for Q1 cows in the present study explained why these individuals also had fewer completed lactations. We have previously shown that dairy cows with a low AFC, which presumably also had low AMH concentrations as heifers (Ireland et al., 2011) like the Q1 cows in the present study, also have fewer lactations (1.9 vs. 2.6) compared with their herdmates with the highest AFC (Mossa et al., 2012). Thus, low level of milk production, which is a major reason for culling dairy cows from herds (Bascom and Young, 1998), coupled with our observation that number of completed lactations was decreased, could explain why productive herd life and survival rates were decreased for Q1 compared with Q2 and Q3 cows in our study. In support of this possibility, we observed that, although AMH concentrations were not correlated with level of milk production in our study, Q1 compared with Q2 and Q3 cows had lower levels of milk production during their first lactation but not subsequent lactations. However, the number of Q1 cows culled for voluntary reasons, which included level of milk production ( $\mathrm{n}=$ 3 Q1 cows culled for low level of milk production), was very low during the first lactation and did not differ from Q2 $(\mathrm{n}=1)$, Q3 $(\mathrm{n}=3)$, or Q4 $(\mathrm{n}=3)$. Thus, the $\sim 1,200 \mathrm{~kg}$ lower level of milk production (based on 305-d mature equivalents) during the first lactation for Q1 cows was unlikely to be the main reason why Q1 cows were culled from the herd at a higher rate than Q2 and Q3 cows. Nevertheless, whether relatively low $\mathrm{AMH}$ concentration in heifers is a potential diagnostic marker predictive of level of milk production at least during the first lactation warrants further investigation with larger numbers of animals.

Once we observed that productive herd life and survival rate were both significantly diminished in Q1 compared with Q2 and Q3 cows, the higher culling rate of Q1 cows for all reasons combined (poor reproduction, level of milk production and conformation, health, death, other) was an expected finding in our study. However, results of the multinomial logistic analysis indicated that removal rate for poor reproductive performance (compared with all other reasons for culling) was greater $(P<0.05)$ for Q1 compared with Q2,
Q3, and Q4 cows combined during the first lactation. Thus, the most likely reason why productive herd life and survival rate were diminished in Q1 dairy cows in the present study is that they were culled at higher rates during their first lactation for poor reproductive performance. Despite this finding, several typical measures of reproductive performance (e.g., including age at first AI, at conception, or at each calving, conception rate at first AI, number of times subjected to AI per conception, days open, and calving interval) were similar among cattle, perhaps due to the limited animal numbers in quartiles as mentioned. Nevertheless, results of our study showed that the total percentage of cows pregnant tended $(P<0.10)$ to be lower during each lactation, whereas the average for total percentage of cows pregnant for all lactations combined was significantly $(P<0.01)$ lower for Q1 compared with Q2 or Q3 cows. This observation, coupled with the enhanced culling rates for poor reproductive performance and fewer lactations for Q1 cows, supports the likelihood that heifers with low AMH concentrations have suboptimal fertility.

Results of our present study, however, contrast somewhat with our previous report that evaluated whether fertility differed among dairy cows with low, intermediate, or high AFC (Mossa et al., 2012). In our previous study, dairy cows of mixed ages (up to 8 parities) with a low AFC and presumably low AMH concentrations as heifers (Ireland et al., 2011) had a significantly lower conception rate to first $\mathrm{AI}$, required a greater number of AI to conceive, and had a greater calving interval compared with cows with an intermediate or higher AFC (Mossa et al., 2012). Moreover, overall pregnancy rate was lower for dairy cows with a low compared with a high AFC but not an intermediate AFC (Mossa et al., 2012). The reason for the different outcomes between studies is unknown, but is likely explained either by the limited animal numbers in each AMH quartile in our present study or by a potential age by AFC bias in our previous study (Mossa et al., 2012) that compromised comparisons of results between our previous (Mossa et al., 2012) and the present study. Nevertheless, results of observations on total percentage of cows pregnant in both of our studies combined, coupled with higher culling rates for poor reproduction during the first lactation observed in our present study for Q1 cows, further support the likelihood that dairy heifers with relatively low AMH concentrations may inherently be less fertile.

The absence of differences in conception rates among heifers with different AMH concentrations in the present study was an unexpected observation, especially because ovarian function (Jimenez-Krassel et al., 2009; Mossa et al., 2010), endometrial development (JimenezKrassel et al., 2009), oocyte quality (Ireland et al., 2009), 
and size of the ovarian reserve (Ireland et al., 2008) are diminished in heifers with a low AFC compared with a high AFC (Jimenez-Krassel et al., 2009). Thus, it is tempting to speculate that the aforementioned indices of ovarian function may not have reached a threshold low enough in heifers with low AMH to impair reproductive performance until after birth of their first calf. For example, it is well established that low circulating progesterone concentrations are associated with high rates of embryo mortality in cattle (Inskeep, 2004). Moreover, the enhanced steroid metabolism commonly observed during lactation reduce both progesterone and estradiol production during estrous cycles (Sartori et al., 2002a; Wolfenson et al., 2004), potentially explaining the higher rates of embryo mortality in lactating dairy cows than heifers (Diskin et al., 2011). Perhaps, heifers with relatively low AMH concentrations, which also have decreased progesterone production (Jimenez-Krassel et al., 2009), are more "sensitive" to the physiological responses related to lactation than their herdmates with higher AMH and higher progesterone production. If so, the much lower progesterone production could enhance embryo mortality and explain, for example, why total percentage of cows pregnant is low and culling rates for poor reproductive performance are higher in these individuals compared with their herdmates with higher $\mathrm{AMH}$, as observed in the present study.

\section{CONCLUSIONS}

Because our study was conducted in a single herd with limited numbers of animal $(\mathrm{n}=281)$, it is premature to make an industry-wide recommendation to remove inferior or select superior dairy heifers in a herd based on AMH measurements. Nevertheless, our findings directly support the conclusion that a single determination of $\mathrm{AMH}$ concentration in young adult dairy heifers may be a simple diagnostic method to predict herd longevity, and that AMH may be a useful genetic marker to improve breeding schemes to enhance longevity of dairy cows. This outcome also supports use of the dairy cow model to identify the mechanisms that cause or contribute to the linkage between $\mathrm{AMH}$, size of the ovarian reserve, fertility, level of milk production, and longevity.

\section{ACKNOWLEDGMENTS}

The work was supported by National Research Initiative Competitive Grant no. 2007-35203-18178 and Animal and Food Research Institute Competitive Grant no. 2013-67015-20962 from the USDA National Institute of Food and Agriculture (Washington, DC), and funds from the Michigan Agriculture Experiment Station to
J. J. I., Science Foundation Ireland under Grant 07/ SCR/B1156 to A. C. O. E. and P. L. (opinions, findings and conclusions or recommendations expressed in this material are those of the authors and do not necessarily reflect the views of Science Foundation Ireland). We also thank Green Meadows Farms Inc. (Ovid-Elsie, MI) for use of cattle and Beckman-Coulter Inc. (Brea, CA) for donation of the AMH kits.

\section{REFERENCES}

Bascom, S. S., and A. J. Young. 1998. A summary of the reasons why farmers cull cows. J. Dairy Sci. 81:2299-2305.

Berry, D. P., E. Wall, and J. E. Pryce. 2014. Genetics and genomics of reproductive performance in dairy and beef cattle. Animal 8(Suppl. 1):105-121.

Burns, D. S., F. Jimenez-Krassel, J. L. H. Ireland, P. G. Knight, and J. J. Ireland. 2005. Numbers of antral follicles during follicular waves in cattle: Evidence for high variation among animals, very high repeatability in individuals, and an inverse association with serum follicle-stimulating hormone concentrations. Biol. Reprod. $73: 54-62$.

Cerchiaro, I., M. Cassandro, R. Dal Zotto, P. Carnier, and L. Gallo. 2007. A field study on fertility and purity of sex-sorted cattle sperm. J. Dairy Sci. 90:2538-2542.

Cole, J. B., and P. M. VanRaden. 2009. Net merit as a measure of lifetime profit: 2010 revision AIPL Research Reports. NM\$4 (12-09), Animal Improvement Programs Laboratory, ARS-USDA, Beltsville, MD.

Cushman, R. A., M. F. Allan, L. A. Kuehn, W. M. Snelling, A. S. Cupp, and H. C. Freetly. 2009. Evaluation of antral follicle count and ovarian morphology in crossbred beef cows: Investigation of influence of stage of the estrous cycle, age, and birth weight. J. Anim. Sci. 87:1971-1980.

De Vries, A., M. Overton, J. Fetrow, K. Leslie, S. Eicker, and G. Rogers. 2008. Exploring the impact of sexed semen on the structure of the dairy industry. J. Dairy Sci. 91:847-856.

Diskin, M. G., and D. G. Morris. 2008. Embryonic and early foetal losses in cattle and other ruminants. Reprod. Domest. Anim. 43(Suppl. 2):260-267.

Diskin, M. G., M. H. Parr, and D. G. Morris. 2011. Embryo death in cattle: An update. Reprod. Fertil. Dev. 24:244-251.

El-Zarkouny, S. Z., J. A. Cartmill, B. A. Hensley, and J. S. Stevenson. 2004. Presynchronization of estrous cycles before Ovsynch and progesterone in dairy cows: Ovulation, pregnancy rates and embryo survival. J. Dairy Sci. 87:1024-1037.

Hohenboken, W. D. 1999. Applications of sexed semen in cattle production. Theriogenology 52:1421-1433.

Inskeep, E. K. 2004. Preovulatory, postovulatory, and postmaternal recognition effects of concentrations of progesterone on embryonic survival in the cow. J. Anim. Sci. 82(E-Suppl.):E24-E39.

Ireland, J. J., G. W. Smith, D. Scheetz, F. Jimenez-Krassel, J. K. Folger, J. L. H. Ireland, F. Mossa, P. Lonergan, and A. C. O. Evans. 2011. Does size matter in females? An overview of the impact of the high variation in the ovarian reserve on ovarian function and fertility, utility of anti-Mullerian hormone as a diagnostic marker for fertility and causes of variation in the ovarian reserve in cattle. Reprod. Fertil. Dev. 23:1-14.

Ireland, J. J., F. Ward, F. Jimenez-Krassel, J. L. H. Ireland, G. W. Smith, P. Lonergan, and A. C. O. Evans. 2007. Follicle numbers are highly repeatable within individual animals but are inversely correlated with FSH concentrations and the proportion of goodquality embryos after ovarian stimulation in cattle. Hum. Reprod. $22: 1687-1695$.

Ireland, J. J., A. E. Zielak-Steciwko, F. Jimenez-Krassel, J. Folger, A. Bettegowda, D. Scheetz, S. Walsh, F. Mossa, P. G. Knight, G. W. Smith, P. Lonergan, and A. C. O. Evans. 2009. Variation in the ovarian reserve is linked to alterations in intrafollicular estradiol 
production and ovarian biomarkers of follicular differentiation and oocyte quality in cattle. Biol. Reprod. 80:954-964.

Ireland, J. L. H., D. Scheetz, F. Jimenez-Krassel, A. P. N. Themmen, F. Ward, P. Lonergan, G. W. Smith, G. I. Perez, A. C. O. Evans, and J. J. Ireland. 2008. Antral follicle count reliably predicts number of morphologically healthy oocytes and follicles in ovaries of young adult cattle. Biol. Reprod. 79:1219-1225.

Jimenez-Krassel, F., J. Folger, J. L. H. Ireland, G. W. Smith, X. Hou, J. S. Davis, P. Lonergan, A. C. O. Evans, and J. J. Ireland. 2009. Evidence that high variation in ovarian reserves of healthy young adults has a negative impact on the corpus luteum and endometrium during reproductive cycles of single-ovulating species. Biol. Reprod. 80:1272-1281.

Kevenaar, M. E., M. F. Meerasahib, P. Kramer, B. M. N. van de Lang-Born, F. H. de Jong, N. P. Groome, A. P. N. Themmen, and J. A. Visser. 2006. Serum anti-Mullerian hormone levels reflect the size of the primordial follicle pool in mice. Endocrinology $147: 3228-3234$.

La Marca, A., G. Stabile, A. C. Artenisio, and A. Volpe. 2006. Serum anti-Mullerian hormone throughout the human menstrual cycle. Hum. Reprod. 21:3103-3107.

La Marca, A., and A. Volpe. 2006. Anti-Mullerian hormone (AMH) in female reproduction: Is measurement of circulating $\mathrm{AMH}$ a useful tool? Clin. Endocrinol. (Oxf.) 64:603-610.

Lehenbauer, T. W., and J. W. Oltjen. 1998. Dairy cow culling strategies: Making economical culling decisions. J. Dairy Sci. 81:264271.

Lucy, M. C. 2001. Reproductive loss in high-producing dairy cattle: Where will it end? J. Dairy Sci. 84:1277-1293.

Malhi, P. S., G. P. Adams, and J. Singh. 2005. Bovine model for the study of reproductive aging in women: follicular, luteal, and endocrine characteristics. Biol. Reprod. 73:45-53.

Mossa, F., F. Jimenez-Krassel, J. K. Folger, J. L. Ireland, G. Smith, P. Lonergan, A. C. O. Evans, and J. J. Ireland. 2010. Evidence that high variation in antral follicle count during follicular waves is linked to alterations in ovarian androgen production in cattle. Reproduction 140:713-720.

Mossa, F., S. W. Walsh, S. T. Butler, D. P. Berry, F. Carter, P. Lonergan, G. W. Smith, J. J. Ireland, and A. C. O. Evans. 2012. Low numbers of ovarian follicles $\geq 3 \mathrm{~mm}$ in diameter are associated with low fertility in dairy cows. J. Dairy Sci. 95:2355-2361.

Núñez-Dominguez, R., L. V. Cundiff, G. E. Dickerson, K. E. Gregory, and R. M. Koch. 1991. Lifetime production of beef heifers calving first at two vs three years of age. J. Anim. Sci. 69:3467-3479.

Pankowski, J. W., D. M. Galton, H. N. Erb, C. L. Guard, and Y. T. Gröhn. 1995. Use of prostaglandin F2 $\alpha$ as a postpartum reproductive management tool for lactating dairy cows. J. Dairy Sci. 78:1477-1488.
Pursley, J. R., M. O. Mee, and M. C. Wiltbank. 1995. Synchronization of ovulation in dairy cattle using $\mathrm{PGF}_{2 \alpha}$ and $\mathrm{GnRH}$. Theriogenology 44:915-923.

Rico, C., S. Fabre, C. Medigue, N. d. Clemente, F. Clement, M. Bontoux, J.-L. Touze, M. Dupont, E. Briant, B. Remy, J.-F. Beckers, and D. Monniaux. 2009. Anti-Mullerian hormone is an endocrine marker of ovarian gonadotropin-responsive follicles and can help to predict superovulatory responses in the cow. Biol. Reprod. 80:50-59

Rico, C., C. Médigue, S. Fabre, P. Jarrier, M. Bontoux, F. di Clémente, and D. Monniaux. 2011. Regulation of anti-Müllerian hormone production in the cow: A multiscale study at endocrine, ovarian, follicular, and granulosa cell levels. Biol. Reprod. 84:560-571.

Sartori, R., G. J. M. Rosa, and M. C. Wiltbank. 2002a. Ovarian structures and circulating steroids in heifers and lactating cows in summer and lactating and dry cows in winter. J. Dairy Sci. 85:2813-2822.

Sartori, R., R. Sartor-Bergfelt, S. A. Mertens, J. N. Guenther, J. J. Parrish, and M. C. Wiltbank. 2002b. Fertilization and early embryonic development in heifers and lactating cows in summer and lactating and dry cows in winter. J. Dairy Sci. 85:2803-2812.

SAS Institute. 2010. SAS/SASTAT Software. Release 9.3, SAS Institute Inc., Cary, NC.

Seidel, G. E. 2010. Brief introduction to whole-genome selection in cattle using single nucleotide polymorphisms. Reprod. Fertil. Dev. $22: 138-144$.

Singhapol, C., and C. J. C. Muller. 2011. Factors affecting longevity in dairy cattle: A review. Agriprobe 8:10-13.

VanRaden, P. M., and J. B. Cole. 2014. Net merit as a measure of lifetime profit: 2014 revision. Animal Improvement Programs Laboratory, ARS-USDA, Beltsville, MD.

VanRaden, P. M., C. M. B. Dematawewa, R. E. Pearson, and M. E. Tooker. 2006. Productive life including all lactations and longer lactations with diminishing credits. J. Dairy Sci. 89:3213-3220.

VAS. 2011. Dairy Comp 305 Software. Version 8. Valley Agriculture Software, Tulare, CA. http://www.vas.com/dairycomp.jsp.

Walsh, S. W., F. Mossa, S. T. Butler, D. P. Berry, D. Scheetz, F. Jimenez-Krassel, R. J. Tempelman, F. Carter, P. Lonergan, A. C. O. Evans, and J. J. Ireland. 2014. Heritability and impact of environmental effects during pregnancy on antral follicle count in cattle. J. Dairy Sci. 97:4503-4511.

Weigel, K. A. 2004. Exploring the role of sexed semen in dairy production systems. J. Dairy Sci. 87(E. Suppl.):E120-E130.

Wolfenson, D., G. Inbar, Z. Roth, M. Kaim, A. Bloch, and R. BrawTal. 2004. Follicular dynamics and concentrations of steroids and gonadotropins in lactating cows and nulliparous heifers. Theriogenology 62:1042-1055. 